\title{
El islam y la República. \\ Un conflicto entre dos identidades
}

\author{
Carmen Innerarity \\ Universidad Pública de Navarra \\ Departamento de Sociología \\ carmeni@unavarra.es
}

\section{Resumen}

El trabajo analiza la relación existente entre las explosiones identitarias neotribales violentas, recientemente acaecidas en Francia, protagonizadas por musulmanes franceses de segunda generación, y el fracaso del proceso de integración social, más bien de inclusión social, en el rol de trabajador de franceses de segunda o tercera generación que viven en el gueto.

Palabras clave: islam, república, conflicto de identidades.

\section{Abstract. Islam and the Republic: The Conflict Among Two Identities}

The paper analyzes the existent relationship betwen the violent neotribal identitarian explosions that recently took place in France, most of them starred by second generation french muslims of, and the defeat of the process of social integration, of social inclusion in the role of worker of second and third generation French who live in the ghetto.

Key words: Islam, Republic, struggle of identities.

\section{Sumario}
1. La (re)construcción
3. Conclusión
de la identidad islámica
Bibliografía

2. La respuesta política: la reafirmación

de la identidad republicana

Durante las primeras etapas de la modernización en Occidente, la lógica fundamental de los conflictos era de carácter político, ligada a los procesos de construcción de los estados nacionales y a la competencia geoestratégica entre ellos. Tras la Revolución Industrial, el paradigma dominante es el de la redistribución de recursos. Pero el capitalismo globalizado y el desarrollo del Estado de bienestar han traído como consecuencia que los conflictos sociales no puedan ser leídos ya bajo la guía de la redistribución, sino que la lucha por el reconocimiento se está convirtiendo rápidamente en la forma paradigmática del conflicto social y político. El paradigma de la distribución de recursos estaría ahora superado por el del reconocimiento de identidades como fuente de conflicto. 
Pero, tal como ha puesto de manifiesto Nancy Fraser en su debate con Axel Honneth (Fraser, 2003), la consideración de que el reconocimiento sea un paradigma alternativo que ha superado a la redistribución puede ser acertada teóricamente, pero no funciona en la práctica, sobre todo cuando queremos analizar situaciones conflictivas concretas, derivadas, por ejemplo, de la etnia o el género. En este trabajo, quiero proponer desde esta perspectiva un análisis de los conflictos que han tenido lugar en el seno de la comunidad inmigrante de origen musulmán en Francia. Conflictos que empezaron con las reivindicaciones culturales en las escuelas a finales de los años ochenta y que han terminado con el estallido de violencia urbana en algunos barrios marginales. Considero que ambos son capítulos de una misma historia que debe entenderse desde la doble perspectiva de redistribución y reconocimiento, y que ha terminado por plantearse como un conflicto entre dos identidades: la identidad (cuasi religiosa) republicana, que se ha ido reafirmando progresivamente, y la identidad de los jóvenes franceses procedentes de la inmigración, que buscan ser reconocidos como ciudadanos de pleno derecho, sin renunciar por ello a su identidad cultural (religiosa).

\section{La (re)construcción de la identidad islamica}

Desde mediados de la década de los cincuenta y hasta los años setenta, la inmigración procedente del norte de Africa experimenta una gran aceleración debido a la descolonización y a las políticas del gobierno francés para reclutar mano de obra industrial. Estas primeras oleadas están compuestas por varones que vienen a Europa con la idea de volver a su país de origen una vez hayan conseguido acumular algún capital. Por este motivo, no se plantean ningún problema de carácter identitario y mantienen sus prácticas religiosas y culturales en su vida privada. Pero con la crisis económica de la década de los setenta y el fin de los llamados «treinta gloriosos», se produce un abandono progresivo de la idea de retorno, entre otras razones, por la imposibilidad de ahorrar y favorecido por la actitud de los gobiernos franceses de la época, que facilitan el reagrupamiento familiar (Pérez Díaz, 2004). La integración se basa en el empleo $\mathrm{y}$ en un cierto aprendizaje de la lengua nacional, que ha dejado subsistir costumbres y formas de organización social propias del país de origen ${ }^{1}$.

El asentamiento definitivo de las familias en el país de acogida y la llegada a la edad adulta de las generaciones musulmanas nacidas en Francia (y actualmente poseedoras de la nacionalidad francesa) contribuyen al estableci-

1. Resulta difícil precisar el número de musulmanes que actualmente residen en Francia, sobre todo a causa de la prohibición de incluir preguntas sobre las propias convicciones religiosas en cuestionarios oficiales. Según los datos del INSEE (Institut National de Statistique et d'Études Économiques), de acuerdo con el último censo de población realizado en 1999, en Francia viven 4.306.094 inmigrantes, aproximadamente un tercio de los cuales (1.556.043) han obtenido la nacionalidad francesa. Un 39\% de ellos proceden del norte de Africa y un 4\%, de Turquía (INSEE, 2005). 
miento duradero de un islam de diáspora, para el cual la perspectiva de un retorno al país de origen ha perdido toda su plausibilidad. Con el abandono del «mito del retorno» masivo al país de origen, la práctica religiosa ha salido del margen comunitario y familiar para integrar los espacios públicos frecuentados por estos nuevos ciudadanos franceses que piden un reconocimiento público del lugar del islam en la República. Esta reivindicación, que se afirma con una fuerza tan grande como la integración económica, social y cultural, es especialmente notoria entre los jóvenes. Para éstos, que son los más vulnerables a las amenazas de exclusión, la religión tiende a convertirse en el lugar de conquista de su dignidad y de la construcción de su individualidad. Los más jóvenes reivindican la posibilidad de vivir pública y colectivamente un islam que consideran una dimensión fundamental de su identidad cultural y social, la única que pueden reivindicar específicamente frente a los «franceses de primera categoría». Viven su religión, cuya herencia rara vez reciben de sus padres, en el seno de una vasta constelación de asociaciones, cuya proliferación subraya la débil estructuración del islam francés y su dispersión en múltiples corrientes. El ámbito escolar ha sido uno de los espacios protagonistas de las demandas de estos jóvenes.

A diferencia de las primeras olas de inmigración, formadas sobre todo por hombres que venían ya adultos, los jóvenes nacidos en Francia se ven obligados a construir su propia identidad con los elementos que tienen a su disposición y, en este sentido, se trata de una opción de carácter más individual que la de sus padres, que se entienden a sí mismos por referencia a sus orígenes. Al mismo tiempo, la inestabilidad propia de las sociedades sometidas al imperativo del cambio refuerza la necesidad de esa reafirmación de la propia identidad a través de la cual los individuos intentan enfrentarse a la condición social y psicológica incierta a la cual este cambio les somete. Tal como señala Cherifi, mediadora del Ministerio de Educación para los conflictos que surgen con los jóvenes estudiantes, el recurso de identidad al islam de las jóvenes generaciones surgidas de la inmigración encuentra su principal explicación en la posición precaria de integración social, económica y cultural (Cherifi, 2005).

Pero también la población francesa se ha visto afectada por estos cambios. Quien se siente atemorizado, atribuye las causas de su miedo al extraño, al extranjero que amenaza con minar las expectativas de movilidad social. Esto ha dado lugar, entre otras cosas, a un proceso de aislamiento de los grupos sociales más pobres en los barrios formados por viviendas de protección social. De manera que, como señala Touraine, «cuanto más progresan los guetos y la exclusión, más se remiten las reacciones de defensa comunitaria a la pertenencia religiosa» (Touraine, 2005, p. 212).

Una gran parte de ese islam reivindicativo que quiere manifestarse en la escuela se construye, así, sobre un fondo de malestar social, económico y cultural, de exclusión social y pobreza (Ramadan, 2002, p. 164). Se trata de un islam "defensivo», de "rechazo» (Samadi, 2003) ante la falta de integración en la sociedad, que les permite crear estructuras asociativas y redes sociales fundadas en la identidad religiosa compartida. Y la llamada "cuestión del velo", 
la reivindicación que más atención pública y política ha reclamado de todas las reivindicaciones identitarias llevadas a cabo, constituye la instrumentalización de un signo cultural y religioso para una reivindicación social: el elevado índice de fracaso escolar, la insuficiente atención prestada a la inserción laboral de los inmigrantes es lo que ha preparado el terreno para el desarrollo del islamismo radical, en el que el velo es sólo un síntoma (Cherifi, 2001). Como el acceso a la sociedad francesa en igualdad de condiciones les es, en parte, imposible, o muy difícil, o lento, el velo es el medio para afirmar una identidad diferente. La demanda de las jóvenes musulmanas respecto a la exención de las normas de indumentaria en las escuelas es un aspecto de esta lucha por la manifestación pública del islam como una forma de expresar el descontento. Como señala Nicole Samadi (2003): «La crisis del foulard no es tanto un signo de vuelta a lo religioso, sino signo de una crisis política, social y cultural; no se trata de que la religión cobre fuerza en las escuelas, sino más bien, de una desestabilización de la escuela por el embate del individualismo. El velo es una fuerza identitaria en un mundo de individualidades; es una forma de decir "Yo existo en tanto que yo misma [...] y quiero hacerme comprender" ". El velo es una reacción ante un sentimiento de exclusión, una búsqueda de reconocimiento social, una manera de construir la propia identidad dentro de la sociedad francesa, más que un acto de fe. Este fenómeno no puede entenderse exclusivamente como expresión de una oposición a Occidente, sino, de acuerdo con Ramadan (2002, p. 165), como expresión de una demanda de poder vivir su identidad islámica en Occidente. No hay que perder de vista que, aunque se habla con frecuencia de «jóvenes inmigrantes», en realidad se trata de jóvenes nacidas en Francia que, con bastante frecuencia, hablan francés, poseen la ciudadanía francesa y quieren ser reconocidas como tales, sin por ello renunciar a su identidad de origen que les proporciona seguridad ante la falta de integración plena en la sociedad francesa. Una parte del problema radica en que estos jóvenes musulmanes franceses ven a la modernidad republicana francesa más como una amenaza que como una oportunidad, lo que produce acciones de protesta, como las más recientes algaradas callejeras en Francia, articuladas como una protesta "neotribalista» como las que puso de manifiesto Michel Maffesoli hace ya diez años.

\section{La respuesta política: la reafirmacion de la identidad republicana}

Desde que, en 1989, surgen los primeros casos de chicas que se niegan a quitarse el velo, la respuesta ha ido evolucionando, desde su aceptación, a partir de la libertad de expresión y de conciencia, hasta su reciente prohibición por ley en marzo de 2004, tras el informe realizado por la Comisión Stasi durante el año 2003. No voy a entrar aquí en la evolución del debate sobre los símbolos religiosos, cuestión que he tratado en otro trabajo (Innerarity, 2005). Sí quiero, sin embargo, analizar el significado de la última respuesta política, la contenida en el informe de la Comisión Stasi, que reafirma el republicanismo como la manera más adecuada de hacer frente a las reivindicaciones y lograr 
la integración de los inmigrantes, cuando quizá desde una perspectiva liberal se podría haber afrontado el tema de una manera más apropiada.

Ya desde los primeros conflictos, el objetivo es lograr la integración, pero la vía negativa liberal de la defensa de la libertad de conciencia y de expresión y la neutralidad de las instituciones públicas va perdiendo fuerza en el discurso político frente al ideal republicano de no-dominación, como "la posición de que disfruta alguien cuando vive en presencia de otros, y en virtud de un diseño social, ninguno de ellos le domina» (Pettit, 1999, p. 96) y que está en la base de un estado que interviene para impedir que otros poderes organicen la sociedad (Miller, 1997, p. 217).

Las principales referencias por las que se guían los sectores implicados en los conflictos planteados por las demandas culturales son el dictamen del Consejo de Estado y la circular del entonces ministro de Educación Lionel Jospin, de 1989. Ambos consideran que las alumnas pueden llevar la cabeza cubierta si lo desean, en virtud de la libertad de conciencia. El dictamen señala que «esta libertad reconocida a los alumnos significa el derecho a expresar y manifestar sus creencias religiosas en los establecimientos escolares dentro del respeto al pluralismo y a la libertad de los demás y sin que ello atente contra las actividades de enseñanza, el contenido de los programas o la obligación de asistencia a clase» (dictamen del Consejo de Estado, 1989). La siguiente referencia fundamental es la circular que envía el entonces ministro de Educación François Bayrou (1994) a los directores de los centros escolares. En ella se produce un cierto cambio respecto a la respuesta anterior, porque ya se empieza a hablar de que «la nación no es solamente un conjunto de ciudadanos portadores de derechos individuales, sino que es una comunidad de destino». Considera que las manifestaciones de pertenencia cultural atentarían contra esa comunidad, aunque en la práctica se siguen permitiendo los símbolos religiosos aludiendo a la libertad de expresión y de conciencia. Y la última respuesta significativa a los conflictos planteados por los símbolos religiosos es la contenida en el informe de la Comisión Stasi, de diciembre de 2003, que recomienda prohibir por ley los símbolos religiosos en las escuelas argumentando que «el estado fomenta la consolidación de los valores comunes que fundan los lazos sociales en nuestro país» (Comisión Stasi, 2003).

$\mathrm{Si}$ en las primeras respuestas políticas subyacía una concepción individualista de los derechos culturales, que llevaba a insistir en la libertad de conciencia, lo que ahora se observa es una mayor preocupación por el orden y la cohesión social. Lo que la ley de símbolos pretende es encontrar un equilibrio entre los principios de protección de las libertades individuales y los principios que contribuyen a la cohesión social. Más aún, no se trata solamente de lo social en general, sino de los lazos específicos de esta sociedad particular, derivados de su historia, sus tradiciones, la herencia cultural que le hace ser lo que ella es. Y los valores particulares que se imponen como la condición de supervivencia de esta sociedad, como la articulación entre lo que es ahora y lo que ha sido y será a lo largo del tiempo, en la sociedad francesa se resumen en la idea republicana, en la asimilación republicana que hace depender la inte- 
gración de la completa aceptación de la ley civil y de la profesión de fe patriótica (Coq, 1995, p. 294; Ramadan, 2002, p. 164). Desde la Revolución y las primeras constituciones republicanas, Francia ha defendido la nacionalidad como la adhesión a valores compartidos y no en función de criterios étnicos o raciales. Las ideas francesas de nacionalidad y ciudadanía han sido abiertas e inclusivas, es decir, todo el mundo que habitaba en suelo francés podía convertirse en ciudadano de Francia en la medida en que se comprometiera con los valores franceses. De ahí el énfasis en la integración y el rechazo de toda forma de comunitarismo. El núcleo de la integración es la escuela pública y gratuita. La misión que la República encomienda a la escuela es la de ser «lugares en los que se reproduce una identidad nacional común y donde se prepara a los niños para la ciudadanía democrática» (Miller, 1997, p. 176). El instrumento fundamental para convertir en franceses a los miembros de las diversas comunidades que viven en suelo francés es la educación obligatoria y laica. Ahora los alumnos no son considerados únicamente como usuarios de un servicio público, sino «individuos en construcción dentro de una institución cuya misión es su formación» (Debré, 2003).

Por eso, el informe de la Comisión Stasi no se limita a afirmar la defensa de las libertades de conciencia y expresión y la neutralidad liberal del Estado frente al pluralismo cultural y religioso, en cuyo caso llevar signos de pertenencia religiosa no sería en sí mismo condenable, en la medida en que constituye la expresión de un pluralismo que no pondría en peligro el orden público. Considera que «después de haber oído las posturas de unos y otros, la comisión estima que hoy la cuestión no es de libertad de conciencia, sino de orden público» (Comisión Stasi, 2003). Apuesta, por tanto, por el republicanismo que constituye identidad de la sociedad francesa y que implica un rechazo del hecho identitario. Cualquier reivindicación derivada de la pertenencia identitaria implica una limitación de la ciudadanía universal, sería definirnos a partir de una característica determinada —-musulmán, mujer-, que limitaría el ideal universal y abstracto de ciudadano de la República. El sentido de la Declaración de los Derechos del Hombre y del Ciudadano, de 1789, es la expresión del humanismo abstracto, significa que el ser humano debe ser respetado y reconocido por sí mismo, independientemente de sus pertenencias comunitarias.

Desde esta perspectiva republicana, cualquier manifestación identitaria es segregacionista y la escuela debe afirmar la ley y los principios inviolables de la República, que son la igualdad y la libertad. Los símbolos identitarios son también comunitaristas. Son expresión de una pertenencia religiosa y, por lo tanto, de una diferencia que confina al ciudadano en lo particular. Pero la escuela es un espacio compartido, en el que prima la vida en común y donde la neutralidad y universalidad es lo único que nos garantiza que podamos vivir juntos, construir la comunidad de destino que es la República, algo por lo que el Estado debe velar activamente. Ésa es también, en opinión de Ramadan (2002, p. 206), la raíz de la turbulencia que desencadenan en la vida pública este tipo de cuestiones como el pañuelo o las secciones musulmanas en los cementerios; porque afectan a la pregunta fundamental ¿qué pasará con la identidad 
nacional si la sociedad integra esos comportamientos, esas formas de vestir y esos edificios nuevos tan «extraños» y tan visibles?

En este sentido se expresaba recientemente el ministro delegado para la Enseñanza Escolar, señalando que no se puede reducir la laicidad exclusivamente a la neutralidad (liberal) en relación con las diferentes convicciones religiosas, sino que es preciso defender una visión más activa y positiva, inspirada en un proyecto político: formar ciudadanos, emancipar a los individuos respecto a sus pertenencias identitarias particularistas y proporcionarles libertad de elección. "La laicidad es también, así, un proyecto social: debe permitir que cada uno construya su propio itinerario dentro de la sociedad, haga valer sus talentos, su trabajo y su mérito personal. Se inscribe, de esta manera, dentro del proyecto republicano de promoción e integración en la comunidad sociopolítica mediante la escuela» (Darcos, 2003).

Pero lo que ocurre es que el republicanismo termina por convertirse en una religión civil, una religión universal que rechaza cualquier tipo de disidencia, infidelidad o herejía. Alain Finkielkraut comentaba, refiriéndose a esta cuestión, que estamos acostumbrados a pensar en términos dualistas. Lo temporal, lo espiritual, lo sagrado, lo profano. Y en este dualismo situamos la laicidad del lado de lo profano, de lo temporal. Parece que la religión quiere ejercer una especie de apropiación de lo sagrado, y la laicidad es el rechazo de esa apropiación (Finkielkraut, 2003). En este sentido, como señala Gerd Baumann, «el estado nación tiende a ser secular-ista, pero no es de ninguna manera secular. Es decir, sitúa a las iglesias y al culto en una esfera privada, pero el vacío de retórica mística y de ritual resultante se rellena rápidamente con una cuasireligión creada por el estado» (Baumann, 2001, p. 63). Es decir, la laicidad republicana pretende sustituir la comunidad religiosa por un consenso secular en torno a un marco común neutral desde el punto de vista religioso. Pero ese marco común necesita llenarse de una cultura cívica de carácter cuasi religioso, por lo que cada estado termina creando su propia religión civil que es recreada mediante la educación. Por eso, la escuela no es un espacio profano, la escuela es un templo: el templo de la laicidad republicana.

Y es la entronización de la religión civil republicana en el discurso acerca de la laicidad y la integración de la diversidad religiosa y cultural lo que ha llevado finalmente a la prohibición de los símbolos religiosos. La unidad de la ciudadanía republicana ha adquirido un valor absoluto, cuasi religioso, al que se han subordinado otras cuestiones (Kymlicka, 1997, p. 88). Esa misma insistencia en la religión civil republicana impide hacer frente a la realidad del problema, que radica, fundamentalmente, en la falta de integración social de los inmigrantes.

\section{Conclusión}

Si, como parece, nos encontramos ante un conflicto tanto de redistribución (falta de integración social) como de reconocimiento (construcción de la propia identidad como franceses de origen musulman), el problema no se resolverá 
a base de leyes que prohíban las manifestaciones religiosas, sino mediante reformas sociales que mejoren las condiciones de vida de los jóvenes de origen inmigrante. $\mathrm{Y}$ en este sentido parece que hay una cierta incoherencia con el propio ideal republicano que poco a poco se ha ido reafirmando, y que incluye la independencia socioeconómica como un aspecto fundamental del ideal de no dominación. Como señala Pettit, «si un estado republicano está comprometido con el progreso de la causa de la libertad como no-dominación entre sus ciudadanos, no puede menos de adoptar una política que promueva la independencia socioeconómica» (Pettit, 1999, p. 209).

Por otra parte si, como he señalado, la preocupación constante ante todas las reivindicaciones identitarias ha sido la de lograr la plena integración de esos jóvenes en la sociedad francesa, quizá resultaría más adecuado continuar por la vía liberal, que, según hemos visto, tenía más fuerza en las primeras respuestas a los conflictos. Un liberalismo que defienda la neutralidad del estado en cuestiones culturales, pero un liberalismo que, consciente de que la cultura "proporciona a la gente un contexto de elección significativo, sin limitar su capacidad para cuestionar determinados valores» (Kymlicka, 1996, p. 132), ofrezca algún tipo de acomodo a las diferentes identidades en la forma de reconocimiento de determinados derechos culturales, que permitan su plena integración social. Esto es especialmente importante en el caso de las mujeres, para las que acudir a la escuela con la cabeza cubierta es, probablemente, la única vía de integración y promoción social. No podemos considerar que todas aquellas chicas que pretenden ir a la escuela con la cabeza cubierta proclaman su adhesión a la tradición islámica más radical y un rechazo a la cultura occidental. Una parte importante de ellas pretende combinar su origen familiar con el mundo del saber y de la vida profesional, al cual sólo pueden acceder mediante la escuela. Llevar el velo siempre o de manera ocasional puede ser una acción libremente elegida y dotada de sentido en el marco de la lucha de las mujeres musulmanas por integrarse en la sociedad de acogida. Y ése es el único medio del que disponen para hacerlo. Esas luchas tienen lugar en un mundo de significados que esas mujeres no han elegido. «Biográfica e históricamente, lo involuntario se sitúa mucho antes, constituye el inevitable trasfondo de toda vida social, sea ésta libre o no libre, igual o desigual (Walzer, 2004, p. 39). Por eso, una vez reestablecidos el orden y la paz en la vida escolar, quizás habría que llevar a cabo, como señala Touraine, un juicio crítico sobre nuestra percepción del otro y sobre nuestra frecuente incapacidad para reconocer en el otro el mismo trabajo de combinación de espíritu moderno y adhesión a tradiciones y creencias que nosotros mismos asumimos (Touraine, 2005, p. 197). En definitiva, se trata de ser conscientes de que existe una "pluralidad de los modos históricos de modernización» (Touraine, 2005, p. 214), que no tiene por qué pasar necesariamente por la identidad encarnada en la universalidad abstracta de la ciudadanía republicana. 


\section{Bibliografía}

Avis du Conseil d'État du 27 novembre de 1989. Disponible en: <http://www.ladocumentation.francaise.fr $>$ (septiembre de 2004).

Avis du Conseil d'État du 2 noviembre de 1992. Disponible en: <http://www.ladocumentation.francaise.fr>.

BAUMANN, G. (2001). El enigma multicultural. Un replanteamiento de las identidades nacionales, étnicas y religiosas. Paidós: Barcelona.

BAYROU, F. (1994). Circulaire du 20 septembre 1994: Port des signes ostentatoires dans les établissements scolaires. Disponible en: <http://www.ladocumentation.francaise.fr> (septiembre de 2004).

Cherifi, H. (2001). «Entretien avec Céline Rouden». La Croix. 24 de octubre de 2001. Disponible en: <http://www.la-croix.com>.

CoQ, G. (1995). Laïcité et République. Le lien nécessarie. Paris: Editions du Félin.

DARCOS, X. (2003). Intervención en la mesa redonda École et lä̈cité aujourd'hui, organizada por la Commission des affaires culturelles, familiales et sociales, el 22 de mayo de 2003. Disponible en: <http://www.assemblée-nationale.fr>.

DeBRÉ, J.-L. (2003). Mission d'information sur la question du port des signes religieux a l'école. Disponible en: <http://www.assemblee-nationale.fr/12/rapports/r1275t1-2.asp>.

FinkielKRAUT, A. (2003). Intervención en la mesa redonda École et lä̈cité aujourd'hui, organizada por la Commission des affaires culturelles, familiales et sociales, el 22 de mayo de 2003. Disponible en: <http://www.assemblée-nationale.fr>.

Fraser, N.; Honneth, A. (2003). Umverteilung oder Annerkennung? Frankfurt: Suhrkamp.

INNERARITY, C. (2005). «La polémica sobre los símbolos religiosos en Francia. La laicidad republicana como principio de integración». Revista Española de Investigaciones Sociológicas, núm. 111, p. 139-161.

INSEEE (2005). Institut National de la Statistique et d'Études Économiques. Disponible en: <http://www.insee.fr>.

Jospin, L. (1989). Circulaire du 12 décembre 1989: Laïcité, port de signes religieux par les élèves et caractère obligatoire des enseignements. Disponible en: <http://www.ladocumentation.francaise.fr> (septiembre de 2004).

KyMlicKa, W. (1997). Ciudadanía multicultural. Barcelona: Paidós.

«La Rapport de la Comisión Stasi sur la laïcité». Le Monde, 12 de diciembre de 2003.

MilleR, D. (1997). Sobre la nacionalidad. Autodeterminación y pluralismo cultural. Barcelona: Paidós.

PÉrez DíAz, V. (2004). La inmigración musulmana en Europa. Turcos en Alemania, argelinos en Francia y marroquies en España. Barcelona: Fundación "la Caixa".

PetTiT, P. (1999). Republicanismo. Una teoría sobre la libertad y el gobierno. Barcelona: Paidós.

RAMADAn, T. (2002). El islam minoritario. Cómo ser musulmán en una Europa laica. Barcelona: Bellaterra.

SAMADI, N. (2003). «L'islam, les jeunes et la République». Boletin de ARELC (versión electrónica). Disponible en: <www.arelc.org >.

TOURAINE, A. (2005). Un nuevo paradigma para comprender el mundo de hoy. Barcelona: Paidós.

Walzer, M. (2004). Razón, política y pasión. Tres defectos del liberalismo. Madrid: La Balsa de la Medusa. 